2017-10

\title{
Channelling passion for the ocean towards plastic pollution
}

\author{
Pahl, Sabine
}

http://hdl.handle.net/10026.1/10690

10.1038/s41562-017-0204-4

Nature Human Behaviour

Nature Publishing Group

All content in PEARL is protected by copyright law. Author manuscripts are made available in accordance with publisher policies. Please cite only the published version using the details provided on the item record or document. In the absence of an open licence (e.g. Creative Commons), permissions for further reuse of content should be sought from the publisher or author. 
(1,953 words w/o references)

\title{
Channelling passion for the ocean toward plastic pollution
}

Pahl S. ${ }^{*}$, Wyles, K. J. ${ }^{2}$ and Thompson R. C. ${ }^{3}$

\author{
${ }^{1}$ School of Psychology, University of Plymouth, Plymouth PL4 8AA, UK \\ ${ }^{2}$ School of Psychology, University of Surrey, Guildford, GU2 7XH, UK \\ ${ }^{3}$ School of Biological and Marine Sciences, University of Plymouth, Plymouth PL4 8AA, UK \\ * Corresponding author. E-mail: sabine.pahl@plymouth.ac.uk
}

\begin{abstract}
Summary
Plastic pollution is caused exclusively by humans. It poses growing global threats to the ocean and to society and requires urgent action. Using psychological principles can motivate and implement change by connecting symptoms and sources.
\end{abstract}

\section{Oceans and society at threat}

Oceans have inspired passion in humans over millennia but are increasingly at risk from human behaviour. Marine debris, especially plastics, is a major concern. Plastic materials are inexpensive, durable and lightweight, resulting in widespread use in packaging, healthcare, transport etc. Production has expanded from 5 million tons in the 1950 s to over 300 million tons today, and plastics are predominantly derived from fossil fuels. ${ }^{1}$ Nearly $40 \%$ of plastic materials are used as packaging ${ }^{2}$, most of which is single-use. Using a large proportion of plastics only once before disposal seems frivolous, when plastics could persist in the environment for generations, either in landfill or as litter. Jambeck et al. ${ }^{3}$ have estimated that, at the extreme, between $5-28 \%$ of plastic waste at the country level could be mismanaged and thus be at risk of entering the ocean. Exactly how long plastic persists is not yet clear but conventional plastics do not 'go away' unless incinerated. Rather, they break down from macro-items to smaller particles at the micro- and possibly nano-scale. Items travel considerable distances in the ocean, leading to impacts far from their place of origin including the Arctic and the deep sea. A large body of research now describes the ecological impacts of plastic litter, not just on visually appealing, charismatic marine species, but also on small invertebrates such as shellfish and worms. Negative economic impacts have also been established, for example in the fishing and shipping industries. ${ }^{4}$ Plastic particles have been found in commercially important seafood, in rivers and soils, and in salt for human consumption, although effects on human health are yet unknown. ${ }^{5}$ Plastic pollution may also undermine the psychological benefits people ordinarily receive from coastal environments. ${ }^{6}$

\section{Humans are the cause \& solution}


The accumulation of plastics in the natural environment is exclusively the consequence of human decisions and behaviour, at individual, group and societal levels. Contrary to some other environmental problems (e.g., $\mathrm{CO}_{2}$ emissions), 1) all plastics are human-made; there are no 'natural' sources or variability, and 2) the benefits that plastics bring are not directly linked to the emission of plastics to the environment (whereas conventional energy brings benefits that are directly linked with $\mathrm{CO}_{2}$ emissions). The carbon in plastic remains at the end of the useful service life and is available for recycling. In principle, this means we can reduce plastic input into the environment without loss of benefits to society. Solutions lie in changing perceptions and behaviour right along the supply chain from design, production and use, through to disposal and further use via a circular economy. Social and behavioural scientists need to work with natural and technical scientists to turn people into the solution. Changes that lead to less plastic spilling over into the natural environment will have a twofold benefit - reduced litter and reduced use of fossil fuels in producing plastics.

\section{Symptoms vs. sources}

Effective, acceptable solutions require a strong focus on the core causes and pathways of ocean plastic pollution. However, the problem and sources appear to be somewhat disconnected in the public discourse. The focus has been primarily on the symptoms (the animals or environments harmed by the litter) rather than the causes (how the litter enters the environment, plastic use in society). Media images of ocean plastic pollution tend to show marine mammals or birds caught up in plastic debris, or remote locations smothered in plastic litter, e.g., Henderson Island in the South Pacific. There are communities of people who actively take part in, or support, ocean clean-up activities, likely motivated by feelings of connectedness to the ocean, perceptions of the ocean and ocean activities as precious, worthwhile or even 'cool'. While media images are emotive and such initiatives have important local impact, they may not be sufficiently connected to the real underlying cause - the broader societal systems and habits that make plastic ubiquitous. Effective waste management does not currently tend to have those positive value connotations. Plastic used in daily life may be neutral and innocuous in most people's eyes; it only becomes aversive when it spoils the beautiful natural environment. People's love for the ocean is a powerful motivator but end-of-pipe solutions such clean-ups have, up to now, received greater attention than have systemic approaches to stop the problem at source. This is akin to fixing an overflowing bath by mopping up the water spilling onto the floor rather than turning off the tap.

The combination of practical benefit, wide availability and lack of immediately visible harm when using plastics in daily life makes it harder to establish social norms of less plastic or to motivate people to dispose of plastics properly. It may also conjure up feelings of helplessness and lack of control, against a society that does not appear to care about plastic. Thus the challenge is to connect the ocean with day-to-day decisions and habits and build systems of product design, production, consumption and management that facilitate responsible use of plastics. It is time to go further upstream to understand the socio-technical systems, processes and behaviours that contribute to ocean plastic pollution. In essence the solutions to the problem require individuals and communities to make connections between the issues in the ocean and day to day behaviours and systems.

\section{The role of behavioural sciences}

Ocean plastic pollution poses a challenge similar to other environmental threats because the symptoms (in this case polluted coasts and oceans) are often geographically and temporally remote from the largely land-based causes. It has been argued that such distance is associated with perceived lack of urgency, saliency and relevance, which can hamper effective change. ${ }^{7}$ While people may be better at dealing with problems 'here-and-now' rather than 'there-and-later', rather 
than lament this as a weakness, we should build on what the human mind is good at to find sustainable solutions. ${ }^{8}$ For example, visualisation is a powerful tool for engaging and motivating people and ultimately changing behaviours. Visual images are associated with emotions that help develop memory traces and motivations, bridging abstract intentions to specific actions, especially where problem and solution are disconnected. ${ }^{9,}{ }^{10}$ Could we motivate action on plastic pollution by using powerful images on everyday products? Changes to cigarette packaging have seen the introduction of graphic images showing health impacts to reduce smoking. Applying this approach to plastic products could be one method of linking people's passion for the ocean to plastics use in daily life, potentially resulting in more careful consumption and disposal behaviours (Figure $1^{1}$ ).

Experiential methods could be linked with visual methods. For example, people who were able to see and handle microbeads isolated from cosmetic products reported surprise, a desire for more information and motivation for change. ${ }^{11}$ Stories and narratives are also powerful tools for raising awareness and motivating change. ${ }^{12}$

Other core behavioural science insights can be applied to the problem of ocean plastic pollution, including addressing the determinants of behaviours, such as goals, values, perceived control and social norms. Fear appeals have been widely discussed as a behaviour change tool, e.g., in health research. The general conclusion is that fear messages risk triggering defence motivations and denial, and must be used in connection with empowerment. ${ }^{13}$ Other relevant communication principles have been summarised for the context of climate change. ${ }^{14}$ Communicating information about the problem can be part of a campaign but in and of itself lacks motivational power. ${ }^{15}$ Topdown approaches, following the notion that experts merely need to fill an information deficit, are outdated and often counter-productive. ${ }^{16}$ Because plastic pollution is a societal problem that is deeply connected to established lifestyles and societal systems, we need to understand societal perceptions of the causes and impacts of ocean plastic pollution, and then use these causal mental models to devise solutions. ${ }^{17}$ Finally, initiatives often target children and young people. While many of our hopes lie in young people, they also have a limited pool of worry, and it would be unfair and unrealistic to put the burden entirely on future generations. We need to counter our 60+-years of behavioural training of using single-use plastics in a throwaway culture by applying behavioural research now.

\section{Progress in policy}

Important progress has already been made in reducing plastic pollution. Through a mixture of new research and NGO campaigns, microbeads in cosmetic products have recently seen increased public and political attention, and policies have been introduced in several countries to phase them out. Here, the public challenge about microbeads has helped facilitate policy actions. ${ }^{4}$ Many places around the globe have also banned or introduced levies on plastic bags, e.g., Botswana, the Philippines, Galapagos, the UK. Bans are a powerful system changer because they alter the environment in which behaviour takes place, abolishing the need to make conscious decisions. These policies work best if they are introduced with social attitudes and concerns in mind. For example, in the Philippines, plastic bags blocking waste water systems have been largely responsible for floods with great loss of life. Plastic bag bans have since been introduced, accompanied by communication campaigns resulting in high social acceptance. ${ }^{18}$ In contrast, similar attempts in Brazil were met with consumer and industry resistance. ${ }^{19}$ This highlights the importance of social research

\footnotetext{
${ }^{1}$ Note Figure not available in deposited article. Please e-mail sabine.pahl@plymouth.ac.uk if you require the complete version.
} 
with stakeholders, and of trial schemes, ahead of any planned change, to achieve a state of readiness for transition.

However, policy tools such as levies, fines or incentives address extrinsic rather than intrinsic motivations. Extrinsic motivations are fickle triggers for behaviour. The desired behaviour might stop as soon as the incentives stop, householders may even recycle less with incentive programmes in place ${ }^{20}$, and desirable spillover to other pro-environmental behaviours may be limited. ${ }^{21}$ Psychologically, it would be preferable to build intrinsic motivations for better waste management and recycling. Intrinsic motivations can derive from different sources such as pro-environmental identity, people's passion for or connectedness to the ocean, social norms, and aversion to litter's aesthetic effect on natural environments; they are a better fundament for long-term engagement to reduce ocean plastic pollution. The behavioural sciences can provide such sophisticated analyses of human thought and behaviour, building on work by Kahneman, Tversky and others since the 1970s, and in line with the various volumes of popular psychology on nudging, behavioural insights etc. more recently. Moreover, these behavioural approaches compare favourably with traditional policy tools in terms of cost effectiveness. ${ }^{22}$

\section{Build behavioural science capacity}

Behavioural scientists are increasingly being integrated into natural science research programmes, because there is substantial evidence of harm but puzzlement over the lack of action. Social and behavioural sciences have a lot to offer in addressing 'wicked' problems ${ }^{23}$, where the issue is complex and ubiquitous, with complicated risk-benefit tradeoffs that affect diverse stakeholders and seemingly threaten engrained habits and lifestyles. The behavioural disciplines need to develop and embrace this demand. In addition to their focused, discipline-based training, behavioural scientists need to integrate their knowledge and apply their methods together with other disciplines to tackle societal and global challenges. Such capacity building could improve the sometimes negative reputation of "applied" research (e.g., in Psychology) and might bridge internal debates about different methods and perspectives (e.g. qualitative versus quantitative). There may even be value in training behavioural scientists in using terminology or metrics that policymakers are more familiar with (e.g., cost-effectiveness of interventions) to help communication and impact.

\section{Conclusion}

Only together can we design systems that fit people and the environment. There are solutions to ocean plastic pollution, but we need to work together across disciplines and sectors and build on the strengths of humans to facilitate change. For these changes to become catalytic they must be socially acceptable as well as economically and technically viable.

Acknowledgements: We thank Mathew P. White for comments on an earlier version of this manuscript. Competing interests: The authors declare no competing interests. 


\section{References}

${ }^{1}$ Geyer, R., Jambeck, J. R., \& Law, K. L. (2017). Production, use, and fate of all plastics ever made. Science Advances, 3(7), e1700782.

${ }^{2}$ PlasticsEurope (2016). "Plastics -the facts 2016". http://www.plasticseurope.org/documents/document/20161014113313plastics_the_facts_2016_final_version.pdf

${ }^{3}$ Jambeck, J. R., Geyer, R., Wilcox, C., Siegler, T. R., Perryman, M., Andrady, A., Natayan, R. \& Law, K. L. (2015). Plastic waste inputs from land into the ocean. Science, 347(6223), 768-771.

${ }^{4}$ GESAMP (2016). "Sources, fate and effects of microplastics in the marine environment: part two of a global assessment" (Kershaw, P.J., and Rochman, C.M., eds). (IMO/FAO/UNESCO-

IOC/UNIDO/WMO/IAEA/UN/ UNEP/UNDP Joint Group of Experts on the Scientific Aspects of Marine Environmental Protection). Rep. Stud. GESAMP No. 93, 220 p.

${ }^{5}$ Wright, S. L., \& Kelly, F. J. (2017). Plastic and human health: a micro issue?. Environmental Science \& Technology.

${ }^{6}$ Wyles, K. J., Pahl, S., Thomas, K. \& Thompson, R. C. (2015). Factors that can undermine the psychological benefits of coastal environments: Exploring the effect of tidal state, presence, and type of litter. Environment and Behavior, 48(9), 1095-1126.

${ }^{7}$ Moser, S. C., \& Dilling, L. (2007). Toward the social tipping point: creating a climate for change. Creating a climate for change: Communicating climate change and facilitating social change, 491-516. Cambridge University Press.

${ }^{8}$ Pahl, S., Sheppard, S. R. J., Boomsma, C. \& Groves, C. (2014).Perceptions of time in relation to climate change. Wiley Interdisciplinary Reviews (WIREs) Climate Change, 5, 375-388.

${ }^{9}$ Pahl, S., Goodhew, J., Boomsma, C. \& Sheppard, S. R. J. (2016). The role of energy visualisation in addressing energy use: Insights from the eViz project. Frontiers in Psychology: Personality and Social Psychology, 7, 92.

${ }^{10}$ Boomsma, C., Pahl, S., \& Andrade, J. (2016). Imagining Change: An Integrative Approach toward Explaining the Motivational Role of Mental Imagery in Pro-environmental Behavior. Frontiers in Psychology, 7.

${ }^{11}$ Anderson, A.G., Grose, J., Pahl, S., Thompson, R. C., \& Wyles, K. J. (2016). Microplastics in personal care products: Exploring perceptions of environmentalists, beauticians and students. Marine Pollution Bulletin, 113, 454-460.

${ }^{12}$ Dahlstrom, M. F. (2014). Using narratives and storytelling to communicate science with nonexpert audiences. Proceedings of the National Academy of Sciences, 111(Supplement 4), 13614-13620.

${ }^{13}$ Peters, G.-J. Y., Ruiter, R. A. C. \& Kok, G. (2013) Threatening communication: a critical re-analysis and a revised meta-analytic test of fear appeal theory, Health Psychology Review, 7:sup1, S8-S31.

${ }^{14}$ Center for Research on Environmental Decisions and ecoAmerica. (2014). Connecting on Climate: A Guide to Effective Climate Change Communication. New York and Washington, D.C.

${ }^{15}$ Steg, L., Bolderdijk, J. W., Keizer, K., \& Perlaviciute, G. (2014). An integrated framework for encouraging pro-environmental behaviour: The role of values, situational factors and goals. Journal of Environmental Psychology, 38, 104-115. 
${ }^{16}$ Fischhoff, B. (1995). Risk perception and communication unplugged: twenty years of process. Risk Analysis, 15(2), 137-145.

${ }^{17}$ Morgan G, Fischhoff B, Bostrom A, Lave L, Atman C. (1992). Communicating risk to the public. First, learn what people know and believe. Environmental Science \& Technology, 26, 2048-2056.

${ }^{18}$ https://ocean.si.edu/sites/default/files/Philippines\%20Earth\%20Justice\%20Law\%20Summary.pdf

${ }^{19} \mathrm{http}: / /$ polis.org.br/wp-content/uploads/Beth_plastic_news.pdf

${ }^{20}$ Halvorsen, B. (2012). Effects of norms and policy incentives on household recycling: An international comparison. Resources, Conservation and Recycling 67, 18-26.

${ }^{21}$ Thomas, G. O., Poortinga, W. \& Sautkina, E. (2016). The Welsh Single-Use Carrier Bag Charge and behavioural spillover. Journal of Environmental Psychology, 47, pp. 126-135.

${ }^{22}$ Benartzi, S., Beshears, J., Milkman, K. L., Sunstein, C. R., Thaler, R. H., Shankar, M., Tucker-Ray, W., Congdon, W. J. \& Galing, S. (2017). Should Governments Invest More in Nudging? Psychological Science, 0956797617702501.

${ }^{23}$ Pahl, S., \& Wyles, K. J. (2017). The human dimension: How social and behavioural research methods can help address microplastics in the environment. Analytical Methods, 9(9), 1404-1411 